\title{
Original
}

\section{A prospective randomized controlled trial of the effects of vitamin D supplementation on long-term glycemic control in type 2 diabetes mellitus of Korea}

\author{
Ohk-Hyun Ryu'), Sungwha Lee ${ }^{1)}$, Jaemyung Yu ${ }^{1)}$, Moon-Gi Choi ${ }^{1)}$, Hyung Joon Yoo $^{1)}$ and Franco Mantero ${ }^{2)}$ \\ 1) Department of Internal Medicine, College of Medicine, Hallym University, Chuncheon, Korea \\ 2) Endocrine Unit, Department of Medicine, University of Padova, Padova, Italy
}

\begin{abstract}
Epidemiologic studies have shown that low vitamin D levels are associated with reduced insulin sensitivity and increased risk of developing type 2 diabetes mellitus (T2DM). However, there is little evidence that vitamin D supplementation improves glucose intolerance. We evaluated the glucose-lowering effect of vitamin D in Korean T2DM subjects. We enrolled $158 \mathrm{~T} 2 \mathrm{DM}$ patients who had stable glycemic control [hemoglobin A1c $(\mathrm{HbA} 1 \mathrm{c})<8.5 \%$ ] and vitamin D levels less than $20 \mathrm{ng} / \mathrm{mL}$. The participants were randomized into two groups: Placebo (100 mg daily of elemental calcium administered twice a day) or Vitamin D (1000 IU daily of cholecalciferol combined with $100 \mathrm{mg}$ of elemental calcium administered twice a day). We compared outdoor physical activity, glycemic control, homeostasis model of assessment - insulin resistance (HOMA-IR), and parathyroid hormone (PTH), during the 24-week intervention. We analyzed the data of 129 participants (placebo $=65$, vitamin $\mathrm{D}=64$ ) who completely followed the protocol. Outdoor physical activity and oral anti-diabetic drugs did not differ between the groups. While there were significant differences in the vitamin D levels $(15.6 \pm 7.1 \mathrm{ng} / \mathrm{mL} v s 30.2 \pm 10.8 \mathrm{ng} / \mathrm{mL}, P<0.001)$ and change in PTH levels $(1.4 \pm 15.3 \mathrm{pg} / \mathrm{mL} v s-5.5$ $\pm 9.8 \mathrm{pg} / \mathrm{mL}, P=0.003)$ between the placebo and vitamin D groups, there were no differences in HbA1c $(7.27 \pm 0.87 \% v s$ $7.40 \pm 0.90 \%)(P=0.415)$ and HOMA-IR. Serum calcium and kidney function results showed that the vitamin D supplementation was safe. While vitamin D supplementation is safe and effective in the attainment of vitamin D sufficiency, it had no effect on long-term glycemic control for T2DM in our study.
\end{abstract}

Key words: Glycosylated hemoglobin, Type 2 diabetes mellitus, Vitamin D deficiency

VITAMIN D deficiency is very common throughout the world $[1,2]$. In Korea, nearly half of people are in a state of deficiency or insufficiency [3]. The main sources of vitamin $\mathrm{D}$ are cutaneous synthesis and dietary ingestion $[4,5]$. Vitamin D concentrations are mainly synchronized to sun-exposure or outdoor physical activity. The contribution of dietary intake in serum vitamin $\mathrm{D}$ levels is small. Therefore, serum vitamin $\mathrm{D}$ values vary in a seasonal manner, with concentrations significantly higher in late summer than those found during late winter $[6,7]$.

It is well established that vitamin D affects bone health via calcium homeostasis [8]. Vitamin D deficiency causes rickets in children and osteomalacia in adults. Recently, many epidemiologic studies have Submitted Aug. 26, 2013; Accepted Oct. 31, 2013 as EJ13-0356 Released online in J-STAGE as advance publication Nov. 16, 2013 Correspondence to: Franco Mantero, Endocrine Unit, Department of Medicine, University of Padova, via Ospedale 105, 35128, Padova, Italy. E-mail: franco.mantero@unipd.it shown that low vitamin D levels are associated with reduced insulin sensitivity and an increased risk of developing type 2 diabetes mellitus (T2DM) [9, 10, 11]. The suggested mechanism is that vitamin D mediates insulin secretion [12] and glucose uptake [13, 14], and also regulates insulin receptor gene expression [15]. Parathyroid hormone (PTH) [16] and osteocalcin [17], osteoblast-derived bone turnover marker, have also been suggested to mediate glucose metabolism in relation to vitamin $\mathrm{D}$.

Although many epidemiologic studies show consistent relationships between vitamin D levels and glucose intolerance, there is little evidence in randomized controlled trials that vitamin D supplementation improves glucose tolerance in pre-diabetes and T2DM. Furthermore, there have been few randomized trials that primarily evaluate the glucose-lowering effect of vitamin D supplementation in T2DM subjects. We performed pilot study including $66 \mathrm{~T} 2 \mathrm{DM}$ patients from 
November 2010 (Autumn) to April 2011 (Spring). In the study, we provided vitamin D 1000IU combined with 500mg of elemental calcium daily for 12 weeks to intervention group or placebo containing $500 \mathrm{mg}$ of elemental calcium. There was no statistically significant effect on glycemic control in seasonal vitamin D supplementation [18]. A recent study that used an ordinary dose of vitamin D (400 IU or 1200 IU) also failed to show any benefit in the parameters of glucose metabolism [19]. However, in another study which used vitamin D 1000 IU-fortified yogurt drink, either with or without added elemental calcium $300 \mathrm{mg}$ daily, improved glycemic status in T2DM patients [20]. Therefore, we designed another 24-week vitamin D supplementation study which increased the dose of vitamin D up to 2000 IU and reduced the dose of elemental calcium to $200 \mathrm{mg}$ daily. The aim of this study was to search for any glucose-lowering effect of vitamin $\mathrm{D}$ and its related mechanism in vitamin D-deficient or -insufficient Korean T2DM subjects.

\section{Methods}

\section{Subjects}

We enrolled subjects with type 2 diabetes from two university hospitals during the winter and early spring season (from December 2011 to March 2012), the period of the lowest vitamin D levels in Korea. Ageing is related to decreased skin vitamin D synthesis and physical activity. HbA1c is subject to change by antidiabetic medication or lifestyle change, such as diet and physical activity. For minimizing these effects, we enrolled participants whose glycemic control were stable and who could continue their usual physical activity during the cold winter period. Enrollment criteria were as follow 1) vitamin D deficient or insufficient status: 25-hydroxy vitamin D [25(OH)D] levels less than $20 \mathrm{ng} / \mathrm{mL}$ [21], 2) ambulatory participants, 3) aged 30 to 69 years, 4) hemoglobin A1c $(\mathrm{HbA} 1 \mathrm{c})<8.5 \%, 5)$ unchanged anti-diabetic medication within 3 months before the study, and 6) normal calcium levels. Patients were excluded from the study based on the following criteria 1) subjects taking medications related to osteoporosis (estrogen, selective estrogen receptor modulator, bisphosphonate, vitamin $\mathrm{D}$, or calcium) within 3 months before the study, 2) use of insulin within 1 month before the study, 3) acute myocardial infarction or stroke within 6 months, 4) abnormal liver function test (alanine aminotransferase or aspartate aminotrans- ferase $\geq 2.5 \times$ upper normal limit) or liver disease (viral hepatitis, autoimmune hepatitis, hemochromatosis, or primary biliary cirrhosis).

\section{Study design}

This study was designed as a prospective, randomized, double-blind, placebo-controlled trial. This interventional trial was conducted at the hospital in the cities of Chuncheon and Seoul in Korea. The study protocol was approved by the ethics committee in each hospital separately (CSHH2011-64). It was also approved by the Korea Food and Drug Administration (KFDA) because the permitted daily drug dose of inactive oral vitamin D3 (cholecalciferol) in Korea is a maximum of 1000 IU (KFDA-11866). All subjects provided written informed consent (ClinicalTrials.gov number, NCT01854463).

A reasonable clinical "rule of thumb" is that the addition of $1000 \mathrm{IU}$ of vitamin D3 daily can be expected to increase circulating $25(\mathrm{OH}) \mathrm{D}$ by approximately $10 \mathrm{ng} /$ $\mathrm{mL}[22,23]$. In our previous pilot study, 25(OH)D levels of Korean T2DM patients were $8.8 \pm 3.2 \mathrm{ng} / \mathrm{mL}$ in winter season (February) and $16.0 \pm 6.0 \mathrm{ng} / \mathrm{mL}$ in summer season (August) [24]. Therefore, we chose 2000 IU of vitamin D3 as an optimal daily supplemental doses for study subjects considering the clinical "rule of thumb".

The following assumptions were used to determine the sample size. In our pilot study [18] which had similar protocol to this study except study period and dose of vitamin $\mathrm{D}$, the mean $\mathrm{HbA} 1 \mathrm{c}$ was $7.4 \%$ and standard deviation was $0.6 \%$. Nikooyeh B et al. [20] showed the improvement of glycemic control about $0.4 \%$ with daily vitamin D containing 1000IU yogurt. We assumed that the effect size by vitamin D 2000IU intervention would be $0.3 \%$. The assumption for statistical power of this study was 0.8 and type 1 error was 0.05 . When we calculated the sample size with this assumption, sample size of each group was 64 . We hypothesized the dropout rate as 0.2 during this study period. Therefore the participants of each group was nearly 80. For the recruitment of participants, we mailed to diabetic subjects registered at the hospital and private clinic in Chuncheon and Seoul. From November 2011 to February 2012, we screened 180 participants according to enrollment criteria. Randomization was performed within 1 month from the date of screening.

The participants were randomized to receive either 1000 IU of cholecalciferol (inactive vitamin D3) com- 
bined with $100 \mathrm{mg}$ of elemental calcium (vitamin D group) two times daily or placebo containing $100 \mathrm{mg}$ of elemental calcium two times daily (placebo group) for 24 weeks (Dalim BioTech, Korea) because vitamin D single compound drugs were not permitted by KFDA. The cholecalciferol and placebo tablets were identical in size, color, shape, and ingredients except the doses of cholecalciferol. The randomization was carried out in a 1:1 ratio without blocking using computer-generated random numbers in each hospital. The randomization code was kept in a sealed envelope until the final visit of the last participant. At baseline, $12 \pm 2$, and $24 \pm 4$ weeks, physical examination and blood chemistry were performed in all of the participants. The duration of diabetes and medications (antidiabetic, antihypertensive, statin, fibrate, and antiplatelet agents) of the randomized participants were checked. We identified the presence of retinopathy, nephropathy, and neuropathy.

We also evaluated daytime outdoor physical activity at baseline and at the end of the study. Outdoor physical activity was classified into day-time and 10:00 to 15:00 o'clock activity $[25,26]$. Lifestyle was recorded in terms of smoking (current or past smoker), alcohol (current or past drinker), and exercise. When the participants exercised at least 3 times per week and at least 30 minutes per time, we defined it as regular exercise. The residence was divided into urban area, living in Seoul and rural area, living in Chuncheon. All of the participants were instructed not to change their previous lifestyle, including physical activity and sun-exposure. However, we educated all participants to eat vitamin D- rich diets sufficiently. Anti-diabetic drugs could be changed considering the glycemic state of the participants according to the judgment of their physicians.

\section{Outcomes}

The primary outcome of this study was to evaluate the glucose-lowering effect and mechanisms of vitamin $\mathrm{D}$ in vitamin $\mathrm{D}$-deficient or -insufficient diabetic patients by measuring glucose, $\mathrm{HbAlc}$, and homeostasis model of assessment - insulin resistance (HOMA-IR). We also searched the effect of vitamin D on renal, hepatic, and parathyroid function as secondary outcome.

\section{Anthropometric and biochemical analysis}

The body weight and height were measured while the subjects wore light clothing without shoes. The body mass index (BMI) was calculated as the weight in kilo- grams divided by the height in meters squared. Waist circumference was measured from the narrowest point between the lower borders of the rib cage and the iliac crest. Waist circumference $\geq 90 \mathrm{~cm}$ in men and $\geq 80 \mathrm{~cm}$ in women (International Obesity Task Force criteria for Asian-pacific population) was used to determine abdominal obesity [27]. The blood pressure was measured in the sitting position after a 10 minute rest period. Hypertension was defined over $140 \mathrm{mmHg}$ in systolic pressure or $90 \mathrm{mmHg}$ in diastolic pressure or using antihypertensive medications. Diabetic dyslipidemia was defined over $200 \mathrm{mg} / \mathrm{dL}$ of total cholesterol or over 150 $\mathrm{mg} / \mathrm{dL}$ of triglyceride or less than $40 \mathrm{mg} / \mathrm{dL}(50 \mathrm{mg} / \mathrm{dL}$ in females) of HDL-cholesterol or statin or fibrate therapy. Diabetic retinopathy was defined by abnormal fundoscopic findings. Diabetic nephropathy was defined by urinary albumin excretion over $30 \mathrm{mg} /$ day or $30 \mathrm{mg} / \mathrm{g}$ creatinine on a random urine sample. Diabetic neuropathy was defined by neurologic symptoms.

Blood samples were drawn after an overnight fast and immediately centrifuged for plasma glucose measurement. We used glucose hexokinase method (Hitachi Automatic Analyzer 7600, Hitachi Co, Tokyo, Japan) for glucose measurement. HbAlc was measured by high-performance liquid chromatography (HPLC) method (Bio-Rad VARIANT II TURBO, Hercules, CA, USA). Insulin was measured using a electrochemiluninescence immunoassay method (Roche, Germany). HOMA-IR is calculated using the following formula; fasting glucose $(\mathrm{mg} / \mathrm{dL}) \mathrm{x}$ fasting insulin $(\mu \mathrm{U} /$ $\mathrm{mL}$ ) / 405 [28]. The serum calcium, creatinine, aspartate aminotransferase (AST), and alanine aminotransferase (ALT) were also measured. The serum 25(OH) D was measured using a direct competitive chemiluminescence immunoassay (DiaSorin Liaison, Stillwater, MN, USA). Vitamin D deficiency was defined as a $25(\mathrm{OH}) \mathrm{D}$ of less than $10 \mathrm{ng} / \mathrm{mL}$. Vitamin D insufficiency was defined as a $25(\mathrm{OH}) \mathrm{D}$ of $10.0-19.9 \mathrm{ng} /$ $\mathrm{mL}$ [21]. The target levels of 25(OH)D in intervention group was over $32 \mathrm{ng} / \mathrm{mL}$ [29]. The serum intact PTH was determined using a chemiluminescence immunoassay (Beckman Coulter, USA).

\section{Statistical analysis}

The statistical analysis was performed using SPSS 12.0 software (SPSS Inc, Chicago, USA). The results are expressed as the mean \pm standard deviation (SD) or numbers (percentages). In the data for the skewed distributions, the data are expressed as the 
median and interquartile ranges. We analyzed the data of participants with good compliance, who took more than $80 \%$ of the doses of the study drug and did not change anti-diabetic drugs. Between groups, comparisons were performed using two-tailed Student's t-tests. Categorical variables were compared using the chi-squared test. In the skewed distribution, statistical analysis was performed after logarithmic transformation of the data. In the results of the nationwide Korean vitamin D insufficiency study, predictors independently associated with vitamin D insufficiency were age, sex, body mass index, season, regular walking, and regular exercise [3]. A correlation analysis between vitamin D levels and possible related factors was performed after adjustment for intervention group. In this analysis, we included age, sex. BMI, WC, and outdoor physical activity as related factors. The effect of vitamin D on glycemic control was analyzed using logistic regression analysis after adjusting for confounding factors. Age, sex, residential region, BMI, abdominal obesity,
DM duration, hypertension, dyslipidemia, diabetic complication (retinopathy, nephropathy, neuropathy), regular exercise, history of alcohol and smoking, DM duration, baseline HbA1c, HOMA-IR, outdoor physical activity were selected as confounding factors. A $P$ value less than 0.05 was considered significant.

\section{Results}

180 subjects with T2DM were screened. We randomized 158 participants who met the inclusion and exclusion criteria into a placebo $(n=79)$ or vitamin $D$ group $(n=79)$. Of the 158 randomized participants, 29 were excluded from the analysis: withdrawal of consent $(n=2)$, follow-up loss $(n=1)$, change of anti-diabetic drugs $(n=13)$, and lack of compliance (taking less than $80 \%$ of the study medication doses, $n=13$ ). We analyzed the data of 129 participants (placebo group $=65$, vitamin $\mathrm{D}$ group $=64$ ) who followed the protocol completely (Fig. 1).

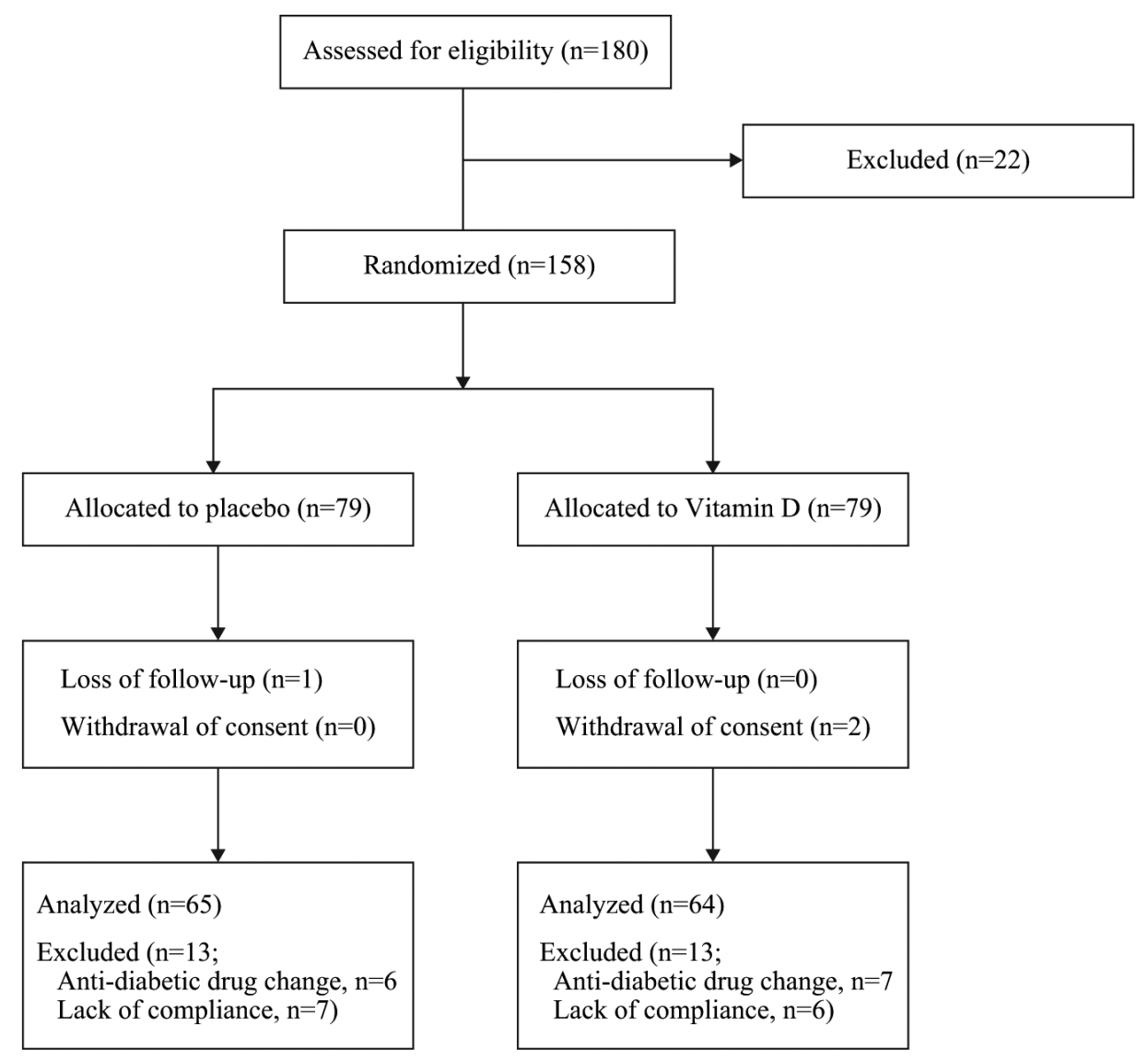

Fig. 1 Study flow diagram 
In the baseline characteristics of the randomized participants, the mean age of the participants was midfifties and mean $25(\mathrm{OH})$ D levels were about $10 \mathrm{ng} /$ $\mathrm{mL}$. Of the randomized participants, $54 \%$ were in a state of vitamin D deficiency. While the two groups were well matched in diabetes duration, fasting glucose, HbA1c, vitamin D levels, PTH, outdoor physical activity, oral anti-diabetic medication, and lifestyle (Table 1), there were marked differences in gender proportion within each group. So we compared some baseline data between men and women. In the baseline vitamin D levels, there were no differences between genders (Table 2).

After the completion of the 24-week intervention, the $25(\mathrm{OH}) \mathrm{D}$ levels reached $15.6 \pm 7.1 \mathrm{ng} / \mathrm{mL}$ and $30.2 \pm 10.8 \mathrm{ng} / \mathrm{mL}$ in the placebo and vitamin $\mathrm{D}$ groups, respectively $(P<0.001)$. In the placebo group, only $4.6 \%(n=3)$ participants had a target level of $25(\mathrm{OH}) \mathrm{D}$ (over $32 \mathrm{ng} / \mathrm{mL}$ ), but in the vitamin D group, $43.8 \%(\mathrm{n}=28)$ reached the target levels of $25(\mathrm{OH}) \mathrm{D}$ $(P<0.001) .25(\mathrm{OH}) \mathrm{D}$ levels of males were higher than that of females $(17.4 \pm 7.8 \mathrm{ng} / \mathrm{mL} v s 13.1 \pm 5.1 \mathrm{ng} /$ $\mathrm{mL} ; P=0.017)$ in placebo group. The pattern was similar in intervention group $(33.8 \pm 10.9 \mathrm{ng} / \mathrm{mL}$ vs 27.0 $\pm 9.7 \mathrm{ng} / \mathrm{mL} ; P=0.011$ ) (data not shown). There were no differences in outdoor physical activity, including activity from 10:00 to 15:00 hour. Although 25(OH)D levels were significantly higher in the vitamin $\mathrm{D}$ group than the placebo group, there was no difference in HbA1c $(7.27 \pm 0.87 \%$ in the placebo group vs $7.40 \pm$ $0.90 \%$ in the vitamin $\mathrm{D}$ group; $P=0.415$ ). In the safety profiles, no participants experienced elevation of creatinine or aminotransferase. The serum calcium level was stable, but the suppression of PTH levels during the intervention were significantly greater in the intervention group than in the placebo group $(-5.5 \pm 9.8 \mathrm{pg} /$ $\mathrm{mL}$ vs $1.4 \pm 15.3 \mathrm{pg} / \mathrm{mL}, P=0.003$ ) (Table 3). Table 4 shows the correlation analysis of final $25(\mathrm{OH}) \mathrm{D}$ levels with other related variables in the study populations. After adjusting for the intervention group, age, sex, and outdoor physical activity were correlated with $25(\mathrm{OH}) \mathrm{D}$ levels. In the logistic regression analysis, glycemic control was not affected by $25(\mathrm{OH}) \mathrm{D}$ levels after adjusting for related variables, such as age, sex, BMI, DM duration, baseline $\mathrm{HbA1c}$, lifestyle, (alcohol, smoking, and regular exercise), HOMA-IR, and outdoor physical activity (Table 5).
Table 1 Baseline characteristics of the study participants $(\mathrm{n}=158)$

\begin{tabular}{|c|c|c|c|}
\hline & Placebo $(n=79)$ & Vitamin D $(n=79)$ & $P$ value \\
\hline Male $(\%)$ & $45(57.0)$ & $34(43.0)$ & 0.08 \\
\hline Age (years) & $55.9 \pm 8.1$ & $54.8 \pm 7.6$ & 0.368 \\
\hline DM duration(years) & $8.0 \pm 5.7$ & $8.3 \pm 5.7$ & 0.677 \\
\hline HbA1c (\%) & $7.29 \pm 0.59$ & $7.30 \pm 0.61$ & 0.926 \\
\hline WC (cm)-Male & $88.6 \pm 8.5$ & $87.8 \pm 5.6$ & 0.682 \\
\hline WC (cm)-Female & $87.4 \pm 9.4$ & $85.6 \pm 8.5$ & 0.168 \\
\hline BMI $\left(\mathrm{kg} / \mathrm{m}^{2}\right)$ & $25.6 \pm 3.6$ & $25.0 \pm 3.3$ & 0.232 \\
\hline Glucose (mg/dL) & $126.6 \pm 19.6$ & $123.4 \pm 21.2$ & 0.462 \\
\hline HOMA-IR ${ }^{*}$ & $2.1(1.4-3.8)$ & $1.9(1.2-3.2)$ & 0.780 \\
\hline $25(\mathrm{OH}) \mathrm{D}(\mathrm{ng} / \mathrm{mL})$ & $10.1 \pm 3.9$ & $10.8 \pm 5.1$ & 0.326 \\
\hline Calcium (mg/dL) & $9.5 \pm 0.6$ & $9.5 \pm 0.6$ & 0.984 \\
\hline Creatinine $(\mathrm{mg} / \mathrm{dL})$ & $0.75 \pm 0.21$ & $0.73 \pm 0.18$ & 0.627 \\
\hline PTH (pg/mL) & $27.2 \pm 13.0$ & $29.9 \pm 12.9$ & 0.211 \\
\hline AST (IU/L) & $28.9 \pm 11.0$ & $26.0 \pm 6.6$ & 0.163 \\
\hline ALT (IU/L) & $30.3 \pm 14.5$ & $27.9 \pm 13.0$ & 0.432 \\
\hline OA(hour) ${ }^{*}$ & $1.5(1.0-4.0)$ & $1.5(0-3.0)$ & 0.427 \\
\hline OA10-15 (hour) ${ }^{*}$ & $1.0(0-2.0)$ & $1.0(0-2.0)$ & 0.426 \\
\hline Alcohol (\%) & $26(52.0)$ & $24(48.0)$ & 0.732 \\
\hline Smoking (\%) & $35(53.8)$ & $30(46.2)$ & 0.419 \\
\hline Regular exercise (\%) & $40(47.1)$ & $45(52.9)$ & 0.425 \\
\hline Hypertension (\%) & $40(50.6)$ & $38(48.1)$ & 0.751 \\
\hline Dyslipidemia (\%) & $69(87.3)$ & $70(88.6)$ & 0.807 \\
\hline Nephropathy $(\%)^{* *}$ & $17(21.5)$ & $17(21.5)$ & 1.000 \\
\hline Neuropathy $(\%)^{* *}$ & $7(8.9)$ & $10(12.7)$ & 0.443 \\
\hline Retinopathy (\%) & $22(27.8)$ & $27(34.2)$ & 0.391 \\
\hline $\mathrm{SU}(\%)^{* *}$ & $53(67.2)$ & $62(78.5)$ & 0.108 \\
\hline $\operatorname{MET}(\%)^{* *}$ & $68(86.1)$ & $70(88.6)$ & 0.632 \\
\hline AGI $(\%)^{* *}$ & $20(25.3)$ & $27(34.2)$ & 0.223 \\
\hline $\operatorname{MEG}(\%)^{* *}$ & $1(1.3)$ & $2(2.5)$ & 0.560 \\
\hline $\mathrm{PIO}(\%)^{* *}$ & $10(12.7)$ & $12(15.4)$ & 0.623 \\
\hline DPP-4I (\%) & $17(21.5)$ & $19(24.1)$ & 0.704 \\
\hline
\end{tabular}

Data are expressed as mean \pm standard deviation.

*Data are expressed as median and interquartile ranges because the data are skewed distribution.

**Data are expressed as numbers and percentages.

AGI, alpha-glucosidase inhibitor; ALT, alanine aminotransferase; AST, aspartate aminotransferase; BMI, body mass index; DM, diabetes mellitus; DPP-4I, dipeptidyl peptidase-4 inhibitor; HbA1c, hemoglobin A1c; HOMA-IR, homeostasis model of assessment insulin resistance; MEG, meglitinide; MET, metformin; OA, daytimeoutdoor physical activity; OA10-15, daytimeoutdoor physical activity from 10 to 15 o'clock; PIO, pioglitazone; PTH, parathyroid hormone; SU, sulfonylurea; $25(\mathrm{OH}) \mathrm{D}, 25$-hydroxy vitamin D 
Table 2 Differences between males and females in some baseline characteristics

\begin{tabular}{lccr}
\hline & Male $(\mathrm{n}=79)$ & Female $(\mathrm{n}=79)$ & $P$ value \\
\hline Height $(\mathrm{m})$ & $1.68 \pm 0.05$ & $1.55 \pm 0.06$ & $<0.001$ \\
BMI $\left(\mathrm{kg} / \mathrm{m}^{2}\right)$ & $25.6 \pm 3.6$ & $25.0 \pm 3.3$ & 0.232 \\
WC $(\mathrm{cm})$ & $88.3 \pm 7.4$ & $85.1 \pm 8.9$ & 0.018 \\
Obesity $(\mathrm{n}, \%)^{*}$ & $28(32.6)$ & $58(67.4)$ & $<0.001$ \\
Glucose $(\mathrm{mg} / \mathrm{dL})$ & $124.1 \pm 27.8$ & $124.0 \pm 26.7$ & 0.983 \\
\hline HOMA-IR* & $1.8(1.2-3.4)$ & $2.5(1.4-3.5)$ & 0.211 \\
HbA1c $(\%)$ & $7.3 \pm 0.6$ & $7.3 \pm 0.6$ & 0.926 \\
25(OH) D $(\mathrm{ng} / \mathrm{mL})$ & $10.1 \pm 3.9$ & $10.8 \pm 5.1$ & 0.328 \\
Calcium $(\mathrm{mg} / \mathrm{dL})$ & $9.5 \pm 0.6$ & $9.5 \pm 0.6$ & 0.984 \\
PTH $(\mathrm{pg} / \mathrm{mL})$ & $27.2 \pm 13.0$ & $29.9 \pm 12.9$ & 0.211 \\
OA & $1.8(1.0-3.0)$ & $1.5(0.0-3.0)$ & 0.719 \\
OA10-15 & $1.0(0.0-2.0)$ & $1.0(0.0-1.5)$ & 0.365 \\
Exercise $(\mathrm{n}, \%)^{*}$ & $55(64.7)$ & $30(35.3)$ & $<0.001$ \\
\hline
\end{tabular}

Data are expressed as mean \pm standard deviation.

*Data are expressed as numbers and percentages.

**Data are expressed as median and interquartile ranges because the data are skewed distribution.

Obesity is defined by waist circumference (male $\geq 90 \mathrm{~cm}$, female $\geq$ $80 \mathrm{~cm}$ ) according to the Asia-Pacific abdominal obesity criteria.

BMI, body mass index; HOMA-IR, homeostasis model of assessment - insulin resistance; OA, daytime outdoor physical activity; OA10-15, daytime outdoor physical activity from 10 to 15 o'clock; PTH, parathyroid hormone; 25( $\mathrm{OH}) \mathrm{D}, 25$-hydroxy vitamin $\mathrm{D} ; \mathrm{WC}$, waist circumference
Table 3 Biochemical and physical activity data after 24-week intervention

\begin{tabular}{lccc}
\hline & Placebo $(\mathrm{n}=65)$ & Vitamin D $(\mathrm{n}=64)$ & $P$ value \\
\hline Male $(\%)$ & $38(58.5)$ & $30(46.9)$ & 0.188 \\
BMI $\left(\mathrm{kg} / \mathrm{m}^{2}\right)$ & $25.4 \pm 3.5$ & $25.2 \pm 3.7$ & 0.865 \\
WC $(\mathrm{cm})-$ Male & $88.3 \pm 8.8$ & $87.5 \pm 6.8$ & 0.465 \\
WC $(\mathrm{cm})$-Female & $87.0 \pm 9.5$ & $85.4 \pm 8.8$ & 0.256 \\
Glucose $(\mathrm{mg} / \mathrm{dL})$ & $123.4 \pm 21.0$ & $122.5 \pm 22.4$ & 0.683 \\
HOMA-IR & $2.1(1.5-3.2)$ & $2.1(1.5-3.8)$ & 0.300 \\
HbA1c $(\%)$ & $7.27 \pm 0.87$ & $7.40 \pm 0.90$ & 0.415 \\
25 $(\mathrm{OH}) \mathrm{D}(\mathrm{ng} / \mathrm{mL})$ & $15.6 \pm 7.1$ & $30.2 \pm 10.8$ & $<0.001$ \\
Calcium $(\mathrm{mg} / \mathrm{dL})$ & $9.4 \pm 0.4$ & $9.4 \pm 0.4$ & 0.802 \\
PTH $(\mathrm{pg} / \mathrm{mL})$ & $27.6 \pm 17.3$ & $23.6 \pm 12.4$ & 0.134 \\
Delta PTH(pg/mL) & $1.4 \pm 15.3$ & $-5.5 \pm 9.8$ & 0.003 \\
Creatinine $(\mathrm{mg} / \mathrm{dL})$ & $0.76 \pm 0.16$ & $0.79 \pm 0.16$ & 0.480 \\
AST $(\mathrm{IU} / \mathrm{L})$ & $25.4 \pm 10.5$ & $21.9 \pm 6.0$ & 0.115 \\
ALT $(\mathrm{IU} / \mathrm{L})$ & $24.7 \pm 11.6$ & $23.5 \pm 11.9$ & 0.691 \\
OA & $2.0(0-3.0)$ & $2.0(0-3.0)$ & 0.480 \\
OA10-15 & $1.0(0-1.5)$ & $0.5(0-1.3)$ & 0.243 \\
\hline Data
\end{tabular}

Data are expressed as mean \pm standard deviation.

* Data are expressed as median and interquartile ranges because the data are skewed distribution.

ALT, alanine aminotransferase; AST, aspartate aminotransferase; BMI, body mass index; Delta PTH, change of parathyroid hormone before and after intervention; HbAlc, hemoglobin A1c; HOMA-IR, homeostasis model of assessment-insulin resistance; OA, daytimeoutdoor physical activity; OA10-15, daytimeoutdoor physical activity from 10 to 15 o'clock; $25(\mathrm{OH}) \mathrm{D}, 25$-hydroxy vitamin D; WC, waist circumference

Table 4 Correlation analysis of final vitamin D levels with related factors adjusting for intervention group

\begin{tabular}{ccccccc}
\hline & Age & Sex & WC & BMI & OA $^{*}$ & OA10-15 \\
\hline \multirow{2}{*}{$25(\mathrm{OH}) \mathrm{D}$} & $\mathrm{r}=0.277$ & $\mathrm{r}=-0.345$ & $\mathrm{r}=0.057$ & $\mathrm{r}=-0.093$ & $\mathrm{r}=0.278$ & $\mathrm{r}=0.347$ \\
& $p=0.021$ & $p=0.004$ & $p=0.641$ & $p=0.445$ & $p=0.021$ & $p=0.003$ \\
\hline
\end{tabular}

*Because of skewed distribution, statistical analysis was performed after logarithmic transformation. BMI, body mass index; OA, daytime outdoor physical activity; OA10-15, daytime outdoor physical activity from 10 to 15 o'clock; WC, waist circumference; 25(OH)D, 25-hydroxy vitamin D

Table 5 Adjusted odds ratio for diabetic glycemic control $(\mathrm{HbA} 1 \mathrm{c}<7 \%)$ according to final vitamin D levels

\begin{tabular}{|c|c|c|c|c|c|}
\hline \multirow{3}{*}{$\begin{array}{c}25(\mathrm{OH}) \mathrm{D} \\
(\mathrm{ng} / \mathrm{mL})\end{array}$} & \multirow{2}{*}{\multicolumn{2}{|c|}{$\begin{array}{l}\text { Glycemic control } \\
(\mathrm{HbA} 1 \mathrm{c}<7 \%)\end{array}$}} & \multicolumn{3}{|c|}{ Adjusted odds ratio (OR) } \\
\hline & & & \multirow{2}{*}{$\begin{array}{c}\text { Model } 1 \\
95 \% \text { CI }\end{array}$} & \multirow{2}{*}{$\begin{array}{c}\text { Model } 2 \\
95 \% \text { CI } \\
\end{array}$} & \multirow{2}{*}{$\begin{array}{c}\text { Model } 3 \\
95 \% \text { CI }\end{array}$} \\
\hline & No $(n)$ & Yes $(n)$ & & & \\
\hline$<20.0$ & 34 & 29 & 1 & 1 & 1 \\
\hline $20.0-29.9$ & 22 & 5 & $0.31(0.09-1.08)$ & $0.21(0.05-0.89)$ & $0.12(0.01-1.43)$ \\
\hline$\geq 30.0$ & 22 & 12 & $0.93(0.31-2.76)$ & $0.89(0.24-3.21)$ & $0.26(0.02-3.79)$ \\
\hline$P$ for trend & & & 0.324 & 0.194 & 0.363 \\
\hline
\end{tabular}

Logistic regression analysis

Model 1: adjusted for age, sex, region, BMI, and abdominal obesity, Model 2: adjusted for Model 1+DM duration, Hypertension, Dyslipidemia,DM complication (nephropathy, neuropathy, retinopathy), history of alcohol, smoking, and regular exercise, Model 3: Model 2+baseline HbA1c, HOMA-IR, and OA BMI, body mass index; HbAlc, hemoglobin A1c; 25(OH)D, 25-hydroxy vitamin D; HOMA-IR, homeostasis model of assessment-insulin resistance; OA, daytime outdoor physical activity 


\section{Discussion}

In this study, we evaluated the effect of 24-week, high-dose vitamin D supplementation on glycemic control in vitamin D deficient or insufficient Korean T2DM patients. Although high-dose vitamin D supplementation was very safe and effective in the achievement of vitamin D sufficiency and suppression of PTH levels, there was no effect in glycemic control in T2DM.

Vitamin D is a well-known hormone that plays an important role in bone and calcium metabolism [8]. Its deficiency is related to rickets in children and osteomalacia in adults. The main sources of vitamin D are cutaneous synthesis and dietary ingestion $[4,5]$. The contribution of dietary intake in serum vitamin D levels is small $[6,7]$. Therefore, the concentrations are mainly synchronized to sun-exposure or outdoor physical activity. Nowadays, vitamin D deficiency is very severe and common all over the world [1,2]. In Korea, nearly half of people are in a state of deficiency or insufficiency. The risk factors of vitamin D deficiency in Korea are young age groups, females, winter and spring seasons, living in an urban area, and indoor occupations [3]. In our study populations, age and outdoor physical activity were positively correlated with vitamin D levels. There are significant differences in serum 25(OH)D levels between male and female. Dong et al. [30 ] showed that 25(OH)D levels were inversely related to BMI, waist circumference, total fat mass, and percentage of fat mass. In general, female has more adiposity than male. Increased clearance of $25(\mathrm{OH}) \mathrm{D}$ due to storage in adipose tissue might cause decline in $25(\mathrm{OH}) \mathrm{D}$ concentrations in females. Female has also less physically active lifestyle. These anthropometric and lifestyle characteristics might cause gender differences in 25(OH)D levels. In our study, during the winter and early spring, the baseline $25(\mathrm{OH}) \mathrm{D}$ levels between genders were well-matched. However, in summer and early autumn, there were significant differences in vitamin D levels. It shows that physical activity during this period deeply affects the levels of vitamin D. The recognition of nonhormonal, intracrine, and paracrine action of vitamin D and its metabolites caused explosive interest in the role of vitamin D [31].

In many epidemiologic studies, vitamin $\mathrm{D}$ deficiency has been linked with cardiovascular risk factors, including diabetes $[32,33]$. In terms of T2DM, vitamin $\mathrm{D}$ and its metabolites appear to have important effects on insulin secretion via pancreatic islets
[12] and insulin action [13, 14], as well as components of inflammation [34, 35] and all of these may have an influence on insulin resistance (IR) and development of T2DM. Vitamin D may modulate the local pancreatic islet renin-angiotensin system (RAS) whilst improving islet beta cell secretory function and prevents or can correct induction of RAS component production under conditions of metabolic stress in vitro studies [36, 37].

There is extensive epidemiologic evidence to strongly suggesting a link between vitamin D deficiency and the development of T2DM [9, 10, 11]. Sunlight during physical activity might be a confounding factor that relates vitamin $\mathrm{D}$ and diabetes. In these observational studies $[9,10,11]$, they took into consideration the synthesis of vitamin D from skin by correcting for season, outdoor physical activity, and lifestyles. Despite careful adjustments for possible confounders including physical activity, residual confounding factors might be influenced on the relation between diabetes and vitamin D levels [38]. In addition, seasonal variations in vitamin $\mathrm{D}$ levels cannot be considered in a cross-sectional study. To overcome these limitations in the epidemiologic studies, several interventional trials were performed to evaluate the effect of vitamin D supplementation in non-diabetic, insulin-resistant subjects [29, 39, 40, 41, 42]. von Hurst et al. [29] supplemented 4000 IU of daily vitamin D3 in insulin resistant south Asian women for 6 months. Significant improvements were seen in insulin sensitivity and IR $(P=0.003$ and 0.02 , respectively), and fasting insulin decreased $(P=$ 0.02 ) with supplementation compared with placebo. IR was most improved when endpoint serum $25(\mathrm{OH})$ $\mathrm{D}$ reached $>$ or $=32 \mathrm{ng} / \mathrm{mL}$ [29]. But in the other trials which supplemented vitamin D3 from 600 to 7000 IU daily or 88,865 IU weekly, there were no amelioration of glucose metabolism, insulin secretion, or inflammatory markers despite the achievement of nearly $70 \mathrm{ng} /$ $\mathrm{mL}$ in $25(\mathrm{OH}) \mathrm{D}$ levels $[39,40,41,42]$. In our study, IR was not improved by vitamin D supplementation. Some studies have evaluated the glucose-lowering effect in T2DM [43, 44], but in most trials including T2DM, the primary outcome of the study did not evaluate the long-term glycemic effect, such as the effect on $\mathrm{HbAlc}$. In one pilot study investigating $\mathrm{HbAlc}$, vitamin D (1200 IU daily) was found to play no role in glycemic control because the doses were not sufficient to achieve target levels(at least $>32 \mathrm{ng} / \mathrm{mL}$ ) of $25(\mathrm{OH})$ D [19]. Jorde et al. also supplemented higher doses of cholecalcifierol (40,000 IU per week) for 6 months for 
T2DM patients but without vitamin D deficiency, there were also no benefits in the fasting glucose and $\mathrm{HbAlc}$ [43]. In a vitamin D-fortified yogurt trial which supplemented vitamin D 1000 IU combined with or without calcium for 12 weeks in T2DM patients, HbA1c was improved but the effect was mediated by the loss of waist circumference and BMI [20].

In this intervention trial, we evaluated the glucoselowering effect of 2000 IU vitamin D3 supplementation for 24 weeks. We screened participants during the period of the lowest vitamin D levels considering seasonal variation in vitamin D. All of the participants were in a state of vitamin D deficiency or insufficiency. After the completion of the 24-week study, nearly $44 \%$ of the participants in vitamin D group had reached the target levels, but in placebo group, only $4.6 \%$ reached the target levels of $25(\mathrm{OH}) \mathrm{D}(>32 \mathrm{ng} /$ $\mathrm{mL}$ ). While hypercalcemia did not develop in this trial, the suppression of PTH was significantly greater in the vitamin $\mathrm{D}$ group than in the placebo group. It has also been hypothesized in some studies that PTH and osteocalcin mediate glucose metabolism $[16,17]$. PTH may induce insulin resistance by the suppression of insulin signaling of adipocytes in hyperparathyroidism [16]. Vitamin D stimulates osteocalcin, an osteoblast-derived bone turnover marker, which may mediate beta-cell proliferation, insulin secretion, and insulin sensitivity [17]. Although PTH was suppressed significantly in the vitamin D group, there was no improvement in long-term glycemic control in this trial.

This trial has some strengths and limitations. For the exclusion of vitamin D synthesis from the skin in participants, we enrolled participants whose physical activity was normal, and checked that outdoor physical activity was comparable in the two study groups. We also excluded the participants whose anti-diabetic medications were changed during the study period for the control of the drug effect in glycemic control. However, this study has several potential limitations. First, we enrolled subjects in the winter and early spring season, the lowest period of vitamin D levels in Korea. In some participants of this trial, vitamin D might be sufficient in other seasons. This might have diminished the differences in glycemic control between the groups by the vitamin D supplementation. Second, only $44 \%$ of the subjects in the vitamin D group reached target levels of vitamin D irrespective of the sampling time in the summer and early autumn, the highest period of vitamin D levels in Korea. Third, the results may also have been confounded by the coadministration of calcium because the KFDA has only approved compounds that combine oral vitamin D3 and calcium. And finally, this research was started from winter and early spring and ended a half year later. During this study period, gradual increase of serum 25(OH)D due to the increase of ultraviolet radiation, which might diminish the efficacy of supplemental oral vitamin D.

This trial shows that use of high-dose vitamin D has no meaningful effect on long-term glucose control and IR in patients with T2DM. This study also suggests that vitamin D supplementation cannot be recommended for the treatment of T2DM in vitamin D-deficient or -insufficient patients. Intervention trials for severe vitamin D-deficient subjects, much higher doses of vitamin $\mathrm{D}$, and long-term period more than 1 -year should be followed to determine which subjects may experience a beneficial effect from vitamin D supplementation in T2DM.

\section{Acknowledgements}

This work was supported by a grant (O.H.R, 2010) from the Korean Diabetes Association. Also this study was supported by the Daewoong Pharmaceutical Company and Handok pharmaceuticals Co., Ltd.

\section{Conflicts of Interest}

None of the authors have any potential conflicts on interest associated with this research.

\section{References}

1. Forrest KY, Stuhldreher WL (2011) Prevalence and correlates of vitamin D deficiency in US adults. Nutr Res 31: 48-54.

2. González-Gross M, Valtueña J, Breidenassel C, Moreno LA, Ferrari M, Kersting M, et al; HELENA Study Group (2012) Vitamin D status among adolescents in
Europe: the Healthy Lifestyle in Europe by Nutrition in Adolescence study. Br J Nutr 107: 755-764.

3. Choi HS, Oh HJ, Choi H, Choi WH, Kim JG, Kim KM, et al. (2011) Vitamin D insufficiency in Korea--a greater threat to younger generation: the Korea National Health and Nutrition Examination Survey (KNHANES) 2008. 
J Clin Endocrinol Metab 96: 643-651.

4. Christakos S, Ajibade DV, Dhawan P, Fechner AJ, Mady LJ (2010) Vitamin D: metabolism. Endocrinol Metab Clin North Am 39: 243-253.

5. Gallagher JC, Peacock M, Yalamanchili V, Smith LM (2013) Effects of vitamin D supplementation in older African American women. J Clin Endocrinol Metab 98: 1137-1146.

6. Andersen R, Brot C, Jakobsen J, Mejborn H, Mølgaard C, Skovgaard LT, et al. (2013) Seasonal changes in vitamin D status among Danish adolescent girls and elderly women: the influence of sun exposure and vitamin D intake. Eur J Clin Nutr 67: 270-274.

7. Freedman DM, Cahoon EK, Rajaraman P, Major JM, Doody MM, Alexander BH, et al. (2013) Sunlight and other determinants of circulating 25 -hydroxyvitamin $\mathrm{D}$ levels in black and white participants in a nationwide U.S. study. Am J Epidemiol 177: 180-192.

8. Lips P, Duong T, Oleksik A, Black D, Cummings S, Cox D, et al. (2001) A global study of vitamin D status and parathyroid function in postmenopausal women with osteoporosis: baseline data from the multiple outcomes of raloxifene evaluation clinical trial. J Clin Endocrinol Metab 86: 1212-1221.

9. Kayaniyil S, Vieth R, Retnakaran R, Knight JA, Qi Y, Gerstein HC, et al. (2010) Association of vitamin D with insulin resistance and beta-cell dysfunction in subjects at risk for type 2 diabetes. Diabetes Care 33: 13791381.

10. Shankar A, Sabanayagam C, Kalidindi S (2011) Serum 25-hydroxyvitamin d levels and prediabetes among subjects free of diabetes. Diabetes Care 34: 1114-1119.

11. Lim S, Kim MJ, Choi SH, Shin CS, Park KS, Jang HC, et al. (2013) Association of vitamin D deficiency with incidence of type 2 diabetes in high-risk Asian subjects. Am J Clin Nutr 97: 524-530.

12. Zeitz U, Weber K, Soegiarto DW, Wolf E, Balling R, Erben RG (2003) Impaired insulin secretory capacity in mice lacking a functional vitamin D receptor. FASEB $J$ 17: 509-511.

13. Zhou QG, Hou FF, Guo ZJ, Liang M, Wang GB, Zhang $X$ (2008) 1,25-Dihydroxyvitamin D improved the free fatty-acid-induced insulin resistance in cultured $\mathrm{C} 2 \mathrm{C} 12$ cells. Diabetes Metab Res Rev 24: 459-464.

14. Manna P, Jain SK (2012) Vitamin D up-regulates glucose transporter 4 (GLUT4) translocation and glucose utilization mediated by cystathionine- $\gamma$-lyase (CSE) activation and $\mathrm{H} 2 \mathrm{~S}$ formation in 3T3L1 adipocytes. $J$ Biol Chem 287: 42324-42332.

15. Calle C, Maestro B, García-Arencibia M (2008) Genomic actions of 1,25-dihydroxyvitamin D3 on insulin receptor gene expression, insulin receptor number and insulin activity in the kidney, liver and adipose tissue of streptozotocin-induced diabetic rats. BMC Mol Biol 9: 65-76.
16. Wu YY, Yu T, Zhang XH, Liu YS, Li F, Wang YY, et al. (2012) 1,25(OH)2D3 inhibits the deleterious effects induced by high glucose on osteoblasts through undercarboxylated osteocalcin and insulin signaling. J Steroid Biochem Mol Biol 132: 112-119.

17. Chang E, Donkin SS, Teegarden D (2009) Parathyroid hormone suppresses insulin signaling in adipocytes. Mol Cell Endocrinol 307: 77-82.

18. Ryu OH, Park J, Yu SH, Kang JG, Kim CS, Lee SJ, et al. (2013) The effect of seasonal vitamin D supplementation on glycemic control in Korea. Program of $2^{\text {nd }}$ International Congress on Diabetes and Metabolism, PE50 (Abstract).

19. Patel P, Poretsky L, Liao E (2010) Lack of effect of subtherapeutic vitamin $\mathrm{D}$ treatment on glycemic and lipid parameters in Type 2 diabetes: A pilot prospective randomized trial. J Diabetes 2: 36-40.

20. Nikooyeh B, Neyestani TR, Farvid M, Alavi-Majd H, Houshiarrad A, Kalayi A, et al. (2011) Daily consumption of vitamin D- or vitamin D + calcium-fortified yogurt drink improved glycemic control in patients with type 2 diabetes: a randomized clinical trial. Am J Clin Nutr 93: 764-771.

21. Institute of Medicine (2011) Dietary reference intakes for calcium and vitamin D. Washington, DC: The National Academies Press.

22. Heaney RP, Davies KM, Chen TC, Holick MF, BargerLux MJ (2003) Human serum 25-hydroxycholecalciferol response to extended oral dosing with cholecalciferol. Am J Clin Nutr 77: 204-210.

23. Binkley N, Ramamurthy R, Krueger D (2010) Low vitamin D status: definition, prevalence, consequences, and correction. Endocrinol Metab Clin North Am 39: 287-301.

24. Lee MY, Ryu OH, Choi MG (2010) Seasonal variations of vitamin D levels in Korean type 2 diabetic patients. Program of $59^{\text {th }}$ scientific sessions of Korean Association of Internal Medicine, S-390 (Abstract in Korean).

25. Kim JH, Moon SJ, Lim SK (1996) Variation of 25-hydroxyvitamin D status according to outdoor activity time (UV exposure) and seasonal change. Korean $J$ Nutrition 29: 1177-1178 (In Korean).

26. Choi YM, Lee JH, Han JS (2009) Effects of vitamin $\mathrm{D}$ and calcium intervention on the improvement of resistance in patients with type 2 diabetes mellitus. Korean Diabetes Journal 33: 324-334 (In Korean).

27. WHO/IASO/IOTF (2000) The Asia-Pacific perspective: redefining obesity and its treatment. Available at http:// www.idi.org.au/obesity_report.htm

28. Matthews DR, Hosker JP, Rudenski AS, Naylor BA, Treacher DF, Turner RC (1985) Homeostasis model assessment: insulin resistance and beta-cell function from fasting plasma glucose and insulin concentrations in man. Diabetologia 28: 412-419. 
29. von Hurst PR, Stonehouse W, Coad J (2010) Vitamin D supplementation reduces insulin resistance in South Asian women living in New Zealand who are insulin resistant and vitamin D deficient - a randomised, placebo-controlled trial. Br J Nutr 103: 549-555.

30. Dong Y, Pollock N, Stallmann-Jorgensen IS, Gutin B, Lan L, Chen TC, et al. (2010) Low25-hydroxyvitamin $\mathrm{D}$ levels in adolescents: race, season, adiposity, physical activity, and fitness. Pediatrics 125: 1104-1111.

31. Hewison M. Vitamin D and innate immunity (2008) Curr Opin Investig Drugs 9: 485-490.

32. Anderson JL, May HT, Horne BD, Bair TL, Hall NL, Carlquist JF, et al; Intermountain Heart Collaborative (IHC) Study Group (2010) Relation of vitamin D deficiency to cardiovascular risk factors, disease status, and incident events in a general healthcare population. Am J Cardiol 106: 963-968.

33. Karakas M, Thorand B, Zierer A, Huth C, Meisinger C, Roden M, et al. (2013) Low levels of serum 25-hydroxyvitamin $\mathrm{D}$ are associated with increased risk of myocardial infarction, especially in women: results from the MONICA/KORAAugsburg case-cohort study. $J$ Clin Endocrinol Metab 98: 272-280.

34. Marcotorchino J, Gouranton E, Romier B, Tourniaire F, Astier J, Malezet C, et al. (2012) Vitamin D reduces the inflammatory response and restores glucose uptake in adipocytes. Mol Nutr Food Res 56: 1771-1782.

35. Reyman M, Verrijn Stuart AA, van Summeren M, Rakhshandehroo M, Nuboer R, de Boer FK, et al. (2013) Vitamin D deficiency in childhood obesity is associated with high levels of circulating inflammatory mediators, and low insulin sensitivity. Int J Obes (in press).

36. Cheng Q, Li YC, Boucher BJ, Leung PS (2011) A novel role for vitamin D: modulation of expression and function of the local renin-angiotensin system in mouse pancreatic islets. Diabetologia 54: 2077-2081.

37. Cheng Q, Boucher BJ, Leung PS (2013) Modulation of hypovitaminosis D-induced islet dysfunction and insulin resistance through direct suppression of the pancreatic islet renin-angiotensin system in mice. Diabetologia 56: 553-562.

38. Mitri J, Muraru MD, Pittas AG (2011) Vitamin D and type 2 diabetes: a systematic review. Eur J Clin Nutr 65: 1005-1015.

39. Wood AD, Secombes KR, Thies F, Aucott L, Black AJ, Mavroeidi A, et al. (2012) Vitamin D3 supplementation has no effect on conventional cardiovascular risk factors: a parallel-group, double-blind, placebo-controlled RCT. J Clin Endocrinol Metab 97: 3557-3568.

40. Muldowney S, Lucey AJ, Hill TR, Seamans KM, Taylor N, Wallace JM, et al. (2012) Incremental cholecalciferol supplementation up to $15 \mu \mathrm{g} / \mathrm{d}$ throughout winter at $51-55^{\circ} \mathrm{N}$ has no effect on biomarkers of cardiovascular risk in healthy young and older adults. $J$ Nutr 142 : 1519-1525.

41. Davidson MB, Duran P, Lee ML, Friedman TC (2013) High-dose vitamin D supplementation in people with prediabetes and hypovitaminosis D. Diabetes Care 36: 260-266.

42. Wamberg L, Kampmann U, Stødkilde-Jørgensen H, Rejnmark L, Pedersen SB, Richelsen B (2013) Effects of vitamin D supplementation on body fat accumulation, inflammation, and metabolic risk factors in obese adults with low vitamin D levels - Results from a randomized trial. Eur J Intern Med 24: 644-649.

43. Jorde R, Figenschau Y (2009) Supplementation with cholecalciferol does not improve glycaemic control in diabetic subjects with normal serum 25-hydroxyvitamin D levels. Eur J Nutr 48: 349-354.

44. Parekh D, Sarathi V, Shivane VK, Bandgar TR, Menon PS, Shah NS (2010) Pilot study to evaluate the effect of short-term improvement in vitamin D status on glucose tolerance in patients with type 2 diabetes mellitus. Endocr Pract 16: 600-608. 